\title{
OPINIÓN
}

\section{IZQUIERDAS, CENTRO IZQUIERDAS Y PROGRESISMOS EN AMÉRICA LATINA HOY ALGUNAS DISTINCIONES}

\author{
Ernesto Ottone
}

\begin{abstract}
El artículo aborda la situación actual de la izquierda en América Latina estableciendo algunas distinciones. A partir del continuum propuesto por Norberto Bobbio, que va desde la extrema izquierda hasta la extrema derecha, se distingue una izquierda neo-jacobina, una izquierda reformadora y una izquierda radical. Se señala que aun cuando las fronteras entre ellas no son siempre claras, tienen visiones muy diferentes entre sí en temas fundamentales relativos a la relación público-privada, el valor de democracia representativa y las libertades individuales.

Junto con indagar en las razones del surgimiento de los distintos tipos de izquierda y las diferencias existentes entre cada experiencia nacional, se ahonda finalmente en los rasgos fundamentales de la perspectiva reformadora, aquella que se defi-
\end{abstract}

ERnesto Ottone. Estudió Sociología en la Universidad Católica de Valparaíso y obtuvo el Doctorado en Ciencias Políticas en la Universidad de París III "La Sorbonne Nouvelle”. Director Cátedra Globalización y Democracia, Universidad Diego Portales. Durante el gobierno de Ricardo Lagos fue director de análisis estratégico de la Presidencia. Autor de numerosas publicaciones, entre sus últimos libros están Después de la Quimera, con Sergio Muñoz (Random Mondadori, 2008) y Ampliando Horizontes: Las Siete Claves Estratégicas del Gobierno de Lagos, con Carlos Vergara (Random Mondadori, 2007). 
ne por aspirar al logro de sociedades más justas sin renunciar a la libertad en nombre de la igualdad y a la igualdad en nombre de la libertad.

Palabras clave: izquierda; neo-jacobinismo; reformismo; igualdad; libertad; democracia.

Recibido: marzo de 2010.

Conviene aclarar al comenzar estas líneas que las distinciones de las cuales nos ocuparemos no se refieren a las diferencias semánticas de los conceptos señalados en el título, que obviamente existen, sino dando por aceptado el uso cercano al sinónimo que ellas han adquirido en el debate público, trataremos de analizar las realidades que ellas, en su conjunto, pretenden cubrir.

Tras la misma denominación, sostenemos que se cubren cosas muy diferentes, siendo dichas diferencias en ocasiones contradictorias e, incluso, parcialmente opuestas.

Iniciaremos nuestro trabajo analizando algunas visiones teóricas que nos permitan distinguir primero el campo de las izquierdas, centro izquierdas y progresismos respecto al campo de derechas, centro derechas y conservantismos.

\section{Algunos elementos teóricos}

Sartori nos dice que la izquierda "debería ser la política que tiene como referente a la ética y rechaza la injusticia". La izquierda está marcada por el altruismo y la derecha por el egoísmo, por el propio bien. Aunque señala que por la "heterogénesis de los fines", en términos de Hegel, el egoísmo puede de pronto favorecer el bien común y el altruismo (con la mejor de las intenciones) causar un daño general. Señala además que por su fundamento altruista la izquierda tiene una exigencia ética mayor y se le perdona menos la corrupción cuando ocupa el poder (Sartori 2009).

Bobbio, cuya elaboración política está enteramente atravesada por su reflexión en torno a la necesidad de conjugar irrenunciablemente la libertad y la igualdad, nos propone en Derecha e Izquierda (Bobbio 1994) un continuum que va desde la visión de extrema izquierda, donde 
la libertad resulta aplastada a través de un autoritarismo igualitario, hasta la extrema derecha que se caracteriza por su doble carácter autoritario y antiigualitario, produciéndose, entre ambos extremos, posiciones menos polarizadas como las de centro izquierda defensoras de la libertad y tendiente a la igualdad y una centro derecha que es partidaria de la libertad, teniendo una vocación menor por la igualdad.

La definición de estas categorías, como en toda su reflexión, no se realiza desde visiones absolutas sino relativas.

Por ello, cuando atribuye a la izquierda una mayor sensibilidad para disminuir desigualdades, no le atribuye la aspiración de un igualitarismo total y tampoco a la derecha una voluntad cerril de conservar todas las desigualdades.

Comentando positivamente a Bobbio, Anthony Giddens, quizás el teórico más exigente e iconoclasta en materia de renovación en la izquierda europea, plantea: "Aunque lo que esté en la izquierda y en la derecha pueda cambiar, nadie puede estar en la derecha y en la izquierda al mismo tiempo" (Giddens 1999).

Si volvemos la mirada hacia América Latina, debemos ser en primer lugar cuidadosos de las definiciones demasiado gruesas. Tal como se generalizó con cierta inexactitud que los años noventa fueron de "giro a la derecha", ha existido una opuesta imprecisión en calificar los años recientes como de "giro generalizado a la izquierda", al menos a la izquierda como singular, sin profundizar diferenciaciones entre izquierdas muy diversas.

Antes de pasar a lo segundo, analicemos lo primero.

El primer elemento paradojal es que ese giro pareciera cristalizarse precisamente en los años en que a América Latina le va bien, entre los años 2003 y 2008. Años que presentan un fuerte crecimiento, que para compararlo en su historia habría que remontar nada menos que cuarenta años. Ese crecimiento con mejor calidad tuvo además mejorías en los indicadores sociales, particularmente en empleo y descenso de la pobreza y la indigencia, y en esos años (lo que no es menor en nuestra frágil historia democrática) la democracia electoral fue la norma.

El cambio producido, aun cuando menos general de lo que aparece y más diverso, resulta menos paradojal si consideramos los años anteriores a la bonanza. En ese caso aparece más como efecto retardado de los resultados mediocres de los años anteriores. 
En efecto, los años noventa y los primeros tres años del presente siglo estuvieron marcados por una fuerte hegemonía del pensamiento económico ortodoxo, neoliberal, con un contrapeso insuficiente de una visión más abierta y progresista como fue la "transformación productiva con equidad" propuesta por CEPAL en 1990, cuyo eco principal lo tuvo en Chile, precisamente el país que constituyó la principal excepción a un desarrollo decepcionante, tremendamente volátil y con magros resultados sociales en la gran mayoría de los países.

Aun cuando hay excepciones parciales en esos años, como Brasil, sólo Chile muestra una tendencia de largo plazo con éxitos relevantes en materia económica, social y en estabilidad política bajo la égida de gobiernos sostenidos por una coalición de centro izquierda, que lo diferencian del resultado mediocre de la región (Castells 2004).

Este balance insatisfactorio de un período prolongado terminó produciendo una profunda frustración, un escepticismo, si no respecto a la democracia, por lo menos frente a los resultados económico-sociales que a ella se le exigen, una percepción de exclusión de una gran parte de la ciudadanía, una visión negativa de una globalización "sin filtros" (O’Donnell 2008) perjudicial para la mayoría y una visión crítica de los gobernantes visualizados como lejanos, cuando no corruptos.

La persistencia de crisis propias y externas (1995, 1998, 2001, 2002) fue acompañada en algunos países con verdaderos derrumbes de los sistemas políticos (Bolivia, Argentina, Ecuador y Venezuela) y un rechazo agrio a los partidos políticos existentes.

Es así como tanto las elecciones realizadas hacia fines del período mediocre y volátil y las efectuadas en el período de bonanza, que concluyó abruptamente el 2008, estuvieron marcadas por un espíritu contestatario y de cambio político, que asumió afortunadamente el camino electoral, a veces en medio de crisis amenazadoras de desenlaces violentos que han sido desgraciadamente demasiado recurrentes en nuestra historia.

En consecuencia, lo que es generalizado es el cambio y el cambio por vía electoral. La reducción de este cambio a un solo tipo, el radicalfundacionalista, aparece como exagerado, más aún si consideramos las elecciones presidenciales más recientes, donde han triunfado, en su mayoría, candidaturas de derecha (Panamá, Honduras, Chile), salvo en el caso de Uruguay. 
Sin embargo, esta mirada es frecuente desde afuera de la región, ya sea en los EE.UU. o en Europa, desde ópticas ideológicas muy diversas. En los EE.UU. de América, por aquellos sectores que continúan influidos por la lógica amigo-enemigo en clave de guerra fría, y en Europa por quienes tienen una insuperable nostalgia por una América Latina turbulenta, excitante y de alto colorido que les generó abundantes emociones fuertes $\mathrm{y}$, a nosotros, experiencias trágicas.

Antes de entrar a hacer distinciones, conviene entonces un baño de realismo. No todos los cambios han tenido orientaciones radicales: Brasil y México, que constituyen más de la mitad de la población latinoamericana y cerca del $70 \%$ del producto interno bruto, figuran en un tramo moderado del continuum de Bobbio, entre el centro izquierda y el centro derecha. El conjunto de las experiencias radicales fundacionalistas abrazan a una fracción mucho menor de la población y su peso económico no supera $10 \%$ del PIB regional.

Una pista interesante y ausente de ideologismos es la que nos entrega Alain Rouquié, quien diferencia los gobiernos caracterizados por el cambio en América Latina entre refundadores y desarrollistas sociales y señala que "Los primeros son gobiernos de ruptura que tienen como objetivo la refundación del sistema político para responder a una presunta demanda de reparación social y moral. Son regímenes a la vez reparadores y refundadores. Los segundos favorecen la continuidad en el campo económico, son constructores de consenso para evitar la inestabilidad política y consideran que la modernización de la economía permitirá responder con eficiencia a las demandas sociales" (Rouquié 2009).

Esta diferenciación resulta interesante porque tiene su fundamento en el particular recorrido histórico que las precede y no en un mundo de opciones infinitas y de pura voluntad. Sin caer en ningún determinismo histórico es necesario, al examinar cada realidad, ver los recorridos políticos, el tipo de discriminación y agravio acumulado, de oportunidades perdidas, de responsabilidad o irresponsabilidad de las clases políticas desplazadas, los niveles de cohesión alcanzados y los niveles de desarrollo logrados.

Sin embargo, comprender las diferencias históricas no significa pasar por alto al menos un núcleo de exigencias del binomio virtuoso libertad-igualdad que deberían ser exigibles a un proyecto político para considerarlo genéricamente progresista. 


\section{Tres distinciones y algo más}

A partir de la afirmación anterior resulta necesario hacer un esfuerzo de distinción entre las izquierdas, centro izquierdas y progresismos latinoamericanos, utilizando como base el continuum de Bobbio. Ello nos permite establecer tres categorías que si bien tienen fronteras porosas entre ellas, también presentan diferencias muy grandes, tan grandes que las convierten en algunos casos en objetos diferentes y hasta contradictorios (Ottone y Muñoz 2008)

2.1. La primera categoría la podríamos llamar neo-jacobina, neo-revolucionaria o refundadora, como lo hace Rouquié. Ella tiende a ser la heredera del jacobinismo tradicional, cuya forma más clásica fue el comunismo que decayó abruptamente con el desaparecimiento del "socialismo real" en Europa del Este en 1989 y cuya constelación actual está formada por Partidos Comunistas más bien reducidos, con su base doctrinaria muy herida y en una búsqueda llena de desasosiego por construir una propuesta actualizada al mundo de hoy. Tal búsqueda se ve agravada por el hecho de que China y Vietnam han inaugurado un nuevo régimen. En el pasado, nosotros conocimos combinaciones de economías de mercado con dictaduras de derecha. Hoy día estamos conociendo economías de mercado muy ortodoxas con dictaduras comunistas, que con una imaginación a prueba de balas explican esta combinación como una fase del camino al comunismo.

En América Latina la herencia jacobina tiende a reciclarse en el neo-jacobinismo, transformándose en una componente subordinada de esta nueva expresión. Su única expresión política se encuentra en una Cuba crepuscular y empobrecida y su expresión como movimiento revolucionario en las FARC colombianas también en declive y empantanadas entre el narcotráfico y las prácticas terroristas.

Lo que sí goza de salud es un neo-jacobinismo variopinto que ha alcanzado la conducción del gobierno en varios países por la vía electoral y que tiene fuerza política en otros.

Se encuentra estructurado más bien en torno a líderes carismáticos que a partidos, los que se sienten más cómodos con estructuras "movimientistas" con fuerte capacidad de movilización callejera, que en partidos propiamente tales.

Surgidos de la democracia electoral, tienden irresistiblemente a generar procesos refundadores, dirigidos a una fuerte acumulación de 
poder en nombre de una misión reparadora que tensa naturalmente el "ethos democrático", la separación de poderes y la libertad de expresión.

Las reglas del juego en el terreno económico, social y político se desplazan y el adversario es considerado siempre un obstáculo al "nuevo mundo". En el terreno internacional la retórica, y en ocasiones la acción, está marcada por el antiimperialismo heredado del jacobinismo clásico, orientado a enfrentarse a los Estados Unidos de América.

Ello resultó claro y popular bajo la administración Bush y se pone cuesta arriba con el gobierno de Obama, quien procura impulsar una política internacional laica y partidaria del multilateralismo.

El neo-jacobinismo tiene un matrimonio mal avenido con la democracia representativa, es una relación de interés donde el amor está ausente, constantemente busca otras experiencias que lo reemplacen, tolera a regañadientes la economía de mercado y más que regularla y supervisarla o desarrollar políticas públicas que operen donde el mercado no opera bien o no opera, tiende a nacionalizar lo privado, más por razones ideológicas que económicas, y propone un "socialismo del siglo XXI", fumoso y cambiante. La globalización no aparece para ellos como un fenómeno ambivalente con oportunidades y riesgos, sino como una pura conspiración de los países ricos.

Su expresión más poderosa es el presidente Chávez y su credo el bolivarianismo. Chávez tiene una vocación intervencionista profunda, la cual crece y decrece con el precio del petróleo y cuya oferta resulta irrefutable para las economías más pequeñas y débiles. Pero de allí no se deriva que constituya una tendencia en expansión. Si observamos de cerca, tiene más fuerza en países de poco desarrollo relativo, sistemas políticos débiles, corruptos o excluyentes, o todo ello junto, donde las clases dirigentes se distanciaron fuertemente del sentir ciudadano y la democracia se vació de sentido.

Cada experiencia tiene sin embargo sus propias características. En Nicaragua y en Honduras las polarizaciones alcanzadas tienen que ver más con la retórica y el poder que con procesos sociales de una orientación definida de cambio progresista en relación a las desigualdades, la pobreza y el ejercicio de los derechos de los sectores populares. En el caso de Honduras ha terminado con un golpe necio e inaceptable, de viejo cuño, dado por una clase dirigente atrabiliaria a un presidente de hablar altisonante, sombrero abundante e ideas escasas y la elección de un presidente conservador cuya legitimidad será afanosa internacionalmente. 
Ese golpe nos mostró un nuevo sentido común latinoamericano que rechaza de inmediato esos métodos, esta vez acompañado por los Estados Unidos de América y el conjunto de la comunidad internacional que, sin embargo, no pudo revertir la situación de manera aceptable para estándares democráticos.

La experiencia hondureña nos muestra a la vez la ausencia de convicción democrática de algunas derechas oligárquicas y los peligros de la frivolidad con ropaje progresista en el poder.

El proceso boliviano, en cambio, tiene una profunda significación política, histórica, sociológica y cultural. Se trata de la llegada al gobierno por vía de la democracia electoral de un indigenismo fuerte, que se siente movilizado y representado por la figura de Evo Morales y se ha constituido en sujeto político.

En este proceso conviven fuerzas muy distintas y no todas de fuertes convicciones democráticas, algunas ni siquiera son partidarias del Estado moderno, que lo ven como una creación impuesta por los invasores, por los "occidentales" (Ottone-Sojo 2008), otros tienen la impronta jacobina clásica en su versión pro-cubana, y otros imaginan una nueva combinación incluyente multicultural.

Ello hace que el justo reclamo de inclusión, de igualdad y de justicia se acompañe de elementos extremos de refundación y de exclusión de los antiguos excluidores. La negociación es tensa y dramática a veces. Da la impresión, en ocasiones, de ser una acción táctica que tiene por norte abrazar más bien una revolución autoritaria que una democracia inclusiva. Como contraparte, la oposición moderada tiende a perder espacio y se produce una polarización llena de peligros políticos e, incluso, territoriales, caracterizada por la emergencia de una oposición dura, de métodos alejados a la negociación democrática e incluso en ocasiones con tintes racistas.

El régimen bolivariano de Chávez en lo interno aparece indeciso en la conformación de una fuerza política que compita de manera transparente en un sistema político democrático "en forma", más parece convencerle una situación movimientista gelatinosa de apoyo al líder o una suerte de democracia directa, "directa, en cuanto a que las órdenes las da directamente" (Rouquié 2009).

Si bien Chávez sigue teniendo una legitimidad democrática de origen y de renovado origen a través de procesos electorales, hasta ahora siempre respetada por su gobierno, teniendo por el contrario al menos 
una parte de su oposición el estigma de un intento de golpe de Estado, su acción de gobierno no tiende a favorecer los métodos democráticos, hace gala de autoritarismo y tiende a controlar todos los espacios de poder. Limita el derecho de expresión y su discurso es siempre amenazante y salpicado de humor cuartelero. En lo concreto su gestión muestra avances económicos y sociales, aunque éstos no guardan relación con los inmensos recursos con los que ha contado por largos años.

La situación de Ecuador es, a su vez, diferente. El presidente Correa surgió como un outsider perfecto frente a un sistema político con poca credibilidad. Él también expresa aspiraciones de justicia, de protección del interés nacional, de refundación. Su fuerza de apoyo se construyó sobre la marcha, incluso a posteriori de su triunfo.

La composición de su gobierno es heterogénea, cambiante y cuenta con algunos sectores que expresan convicciones democráticas. Más allá de la medianía de los resultados de su gestión tiene un fuerte apoyo electoral, pero también una oposición no menor, lo que tiende a morigerar en los hechos sino en las palabras su retórica exaltada y rupturista.

En ocasiones a estas experiencias se tratan de vincular la nueva realidad política salvadoreña encabezada por el presidente Funes y la paraguaya del presidente Lugo. Creo que no es correcto forzar identificaciones de procesos no enteramente definidos que tienen al menos una parte de su mirada en los procesos que Rouquié denomina como "desarrollistas sociales" (Rouquié 2009).

2.2. Volviendo al continuum de Bobbio podríamos establecer una segunda categoría, que denominaríamos como progresismo reformador, lo cual coincidiría con la definición que él da a la centro izquierda: "doctrinas y movimientos a la vez igualitarios y libertarios, para los cuales podríamos usar la expresión 'socialismo liberal' para incluir a todos los partidos socialdemócratas, en sus más diversas praxis políticas" (Bobbio 1999).

Estos partidos, movimientos o coaliciones aparecen sobre todo como herederos de la socialdemocracia europea y en el caso latinoamericano de una tradición demócrata cristiana progresista. Recordemos que en América Latina, salvo de manera muy puntual, no existió una socialdemocracia de origen obrero; la constitución de la socialdemocracia se hizo a través de la búsqueda por parte de la internacional socia- 
lista de partidos afines reformistas, de origen e historias muy diversas, que en algún momento jugaron un rol protagónico en sus países. Hoy muchos de ellos perdieron relevancia y otros surgidos de experiencias reformadoras más recientes han tendido a ocupar su lugar.

Las concepciones que animan este espacio político se caracterizan por la adopción de la democracia procedimental como un valor permanente e irrenunciable, exigiéndole al mismo tiempo una fuerte dimensión igualitaria.

Consideran la economía de mercado como un factor dinamizador de la economía aun cuando no esperan de su lógica ninguna capacidad distributiva capaz de generar una sociedad más igualitaria, ni siquiera producir por sí solo un equilibro económico. A partir del convencimiento de la lógica inequitativa del capitalismo, no se propone destruirlo sino aprovechar su dinamismo para el crecimiento y, al mismo tiempo, desarrollar políticas públicas potentes que morigeren la inequidad y tiendan a sociedades más igualitarias, a ampliar la igualdad de oportunidades y de resultado, a compensar la desigualdad a través de la política y la protección social, generando progresivamente mayores garantías sociales. En definitiva, balanceando la lógica del consumidor, que es desigual, con la lógica de una ciudadanía expandida de tendencia más igualitaria.

Ello requiere de un Estado fuerte, moderno, con capacidad estratégica, no capturado por intereses corporativos, con capacidad y voluntad de intervención que asegure el cumplimiento de las libertades positivas y el cumplimiento progresivo pero pertinaz de los derechos económicos y sociales.

Este progresismo reformador se encarna hoy en partidos y coaliciones de carácter reformista y gradualista, que deben en palabras de Bobbio "Conservar el estandarte de la igualdad repensándola en sus contenidos y uniéndolos a la libertad y la democracia" (Bobbio 1994).

Me atrevería, en América Latina, a colocar en esta categoría la experiencia de la Concertación de Partidos por la Democracia en Chile, sobre todo como balance de sus veinte años de gobierno.

No describiré la experiencia chilena, que de acuerdo a todos los indicadores económicos, sociales y políticos ha sido la más exitosa en la historia de ese país, pues ya lo he hecho en otros escritos (OttonePizarro 2003, Ottone-Vergara 2006, Ottone-Muñoz 2008). En Chile, al contrario que en el exterior, suele abundar una literatura que después de 
señalar al pasar, casi de manera distraída, los logros de esta experiencia, pone el acento en el vaso "medio vacío", en lo no alcanzado y lo que queda por alcanzar.

Esto se caricaturizó hace ya una decena de años en el debate entre "autocomplacientes" y "autoflagelantes", dos conceptos que me parecen ajenos a un progresismo sereno. El primero implica una suerte de pereza intelectual y política, el segundo me parece más adecuado a un tipo de religiosidad autodestructiva.

Creo en cambio que frente a una experiencia básicamente positiva, es necesario tener junto a una apreciación sin complejos de lo alcanzado, una actitud crítica en relación a oportunidades de correcciones de lo hecho mal y de necesidades de cambio en el desarrollo productivo, en la innovación y en el logro de una democracia más amplia e inclusiva y con mucho mayores niveles de igualdad.

El aspecto menos logrado por la experiencia de la Concertación por la Democracia en Chile, que la llevó a perder las elecciones presidenciales en el 2010, no se encuentra en los límites y errores de su acción de gobierno sino en la progresiva pérdida de calidad del quehacer y las prácticas políticas de los partidos que la componen, la ausencia progresiva de sentido colectivo de un número de sus dirigentes y representantes en puestos de elección popular, la preeminencia de lógicas de puro poder, de generación de clientelas en torno a determinados jefes de facción que tienden a fortalecer intereses corporativos en el Estado y a generar una selección adversa del personal político, una escasa renovación generacional y una pérdida de sentir en la coalición como un todo la base de la acción política.

Es necesario señalar que éste no es sólo un problema del progresismo chileno y ni siquiera del progresismo; son fenómenos que recorren a nivel mundial el quehacer político.

En el caso chileno ha influido además un sistema electoral que en nombre de la estabilidad castiga la inclusión, la renovación y la competencia; como asimismo una ley de partidos políticos que deja demasiado margen a la opacidad y muy poco al control ciudadano. A nivel más general, influyen algunos elementos de la tercera distinción que veremos en seguida, más los fenómenos globales de la sociedad de la información y la democracia de la opinión pública (Rodotá 1997, Julliard 2008). 
Considerando que a la derrota política del centro izquierda se suman los efectos de un demoledor terremoto y maremoto que cambia dramáticamente el escenario político para el gobierno y la oposición, se plantea un enorme desafío al centro izquierda chileno para renovarse o incluso refundarse, constituyéndose en una oposición obligatoriamente constructiva y a la vez capaz de construir una propuesta de futuro, que impida una involución conservadora y que sea capaz de encarnarse en liderazgos atractivos y capaz de reconstruir una mayoría.

Aun cuando parezca muy poco ortodoxo, incluiré en esta tendencia tanto al gobierno del partido socialdemócrata encabezado por Fernando Henrique Cardoso, como al gobierno del Partido de los Trabajadores encabezado por Lula. Lo anterior, pese a que ellos se diferencian mucho en origen histórico, en composición y en su autoubicación y discurso, y se relacionan a través del enfrentamiento y la competencia construyendo sus alianzas con otras fuerzas del espectro político brasileño.

Si bien Lula es un factor histórico de inclusión plebeya en la conducción del Estado, él y Cardoso tienen entre sí muchos más elementos en común de lo que nunca reconocerán, tanto en la construcción de un sistema político democrático estable como en la construcción de políticas públicas de orientación progresiva con continuidad en el tiempo.

Incluiría también la experiencia del Frente Amplio de Uruguay, otra experiencia fuerte de coalición, donde a pesar de una cierta retórica nostálgica que puede llamar a engaño y una presencia fuerte de la tercera distinción, ha tendido a prevalecer una práctica progresista sensata, reformista, que no ha roto con el ethos democrático histórico uruguayo, tanto de su sociedad civil como de sus instituciones.

Quizás se podría considerar en esta tendencia, mirando los tiempos largos, la experiencia de Costa Rica con la impronta socialdemócrata del partido de Liberación Nacional en la mayoría de sus gobiernos.

Bajo esas direcciones el conjunto de estos países ha tenido resultados positivos aunque modestos en materia de reducción de desigualdades. Como sabemos, algunos de ellos como Brasil y algo menos Chile vienen de niveles muy negativos en la distribución del ingreso, pero también Uruguay y Costa Rica, que están entre los menos negativos de América Latina, presentan niveles muy altos de desigualdad respecto a los países desarrollados. En materia de descenso de la pobreza y la indigencia el resultado chileno es espectacular y los otros países han tenido resultados importantes, como también en libertades, estabilidad y 
funcionamiento democrático. Si hubiera la posibilidad de hacer una medición estadística de avance de los países como un todo en los últimos años, creo que éstos estarían a la cabeza.

2.3. Siempre siguiendo el continuum de Bobbio, pero al margen de su análisis, me atrevería, como lo he venido anunciando, a distinguir otro tipo de izquierda que con frecuencia está presente, junto a la tendencia anterior, más en las estructuras partidarias que en su acción de gobierno.

Me refiero a una izquierda más radical que no llega a ser neojacobina, pero se instala en zonas fronterizas. Al igual que una buena parte de la izquierda reformadora tiene su origen en la vieja izquierda revolucionaria o en versiones nuevas "antiglobales", o de un ecologismo dogmático.

Esta izquierda ha aceptado las ventajas de la democracia representativa más por necesidad que por convicción, debiendo acoplarse a regañadientes a las experiencias reformadoras o conformando grupos minoritarios que representan el espíritu de la vieja izquierda revolucionaria, intereses de grupos corporativos altamente movilizados, con una retórica de un mundo que sociológicamente cambió, agitando sus banderas con la fe del carbonero. Suspiran por el antiimperialismo de otrora y la modernidad les parece una gran conspiración. Encarnan lo que José Aricó caracterizó como el "pensamiento de la queja” (Aricó 1992).

Todo gradualismo les parece excesivo, reclaman más acción del Estado, pero arriscan la nariz cuando éste actúa sin obedecer a su visión particularista y lo critican entonces como un ente tecnocrático y poco militante.

Aun cuando carecen de una verdadera doctrina como antaño, proponen una difusa democracia participativa concebida no como ampliación de la democracia representativa, sino como su reemplazo.

Esta izquierda, cuando es parte de las coaliciones o partidos reformadores, está siempre cerca de la puerta de salida tanto en Chile, Brasil o Uruguay; dentro de ellas actúan como frondas y siempre sus intereses particulares se recubren de nobles contenidos doctrinarios.

Cuando se separan, normalmente en períodos preelectorales, lo hacen a veces con críticas y argumentos justos pero desinstitucionalizando la política en torno a outsiders mediáticos y mesiánicos, más ligados a instantes de gloria que a los procesos de largo alcance. 
Ella no tiene domicilio fijo, se despliega más como un sentimiento que como una razón. En el caso chileno: "Está representada por quienes forman parte de la coalición (o se han separado momentáneamente), pero van de mala cara por la vida".

Respecto a los logros conseguidos, la primera palabra que se viene a los labios es "pero". Reclaman porque lo hecho, dicen, es sólo lo que se ha podido hacer y no lo que quieren hacer, actitud en realidad bastante cómoda porque siempre podrán argüir que en comparación con la promesa luminosa que está por allá lejos, la realidad será siempre vulgar, poco excitante (Ottone y Muñoz 2008).

Se trata de antisistémicos que viven en el sistema y, en ocasiones, del sistema. No viven con orgullo la reforma y muchas veces suspiran a prudente distancia por los fundacionalismos revolucionarios.

\subsection{Algo más}

Hay otras experiencias que resultan difíciles de caracterizar. Una de ellas es la experiencia peronista de Argentina. El peronismo poco tiene que ver en su origen con la tradición de izquierda en cualquiera de sus versiones, ni en su colocación internacional, ni tampoco en su inspiración originaria, más cercana a visiones corporativistas, ni en su estructura posterior del populismo de Perón, con su componente inclusivo y plebeyo sin ruptura formal con la democracia, ni en su versión neoliberal a lo Menem o en la versión kichnerista de retórica antioligárquica, de alianza hacia el neo-jacobinismo y de un cierto nacionalismo. Poco dado a la negociación y a la construcción de un ethos democrático y de reforzar un sistema político en Argentina, es posible que en el futuro el peronismo deba definirse en términos más universales y con más vocación democrática.

Tampoco en México, fruto de su particular e impresionante historia, termina de constituirse una izquierda democrática, desligada de la tradición autoritaria y vertical de los largos años post revolucionarios.

En otros casos, los partidos de una izquierda reformista no tienen espacio producto de la persistencia del enfrentamiento armado como en el caso de Colombia, o no tienen vocación o posibilidad de realizar reformas y se conforman con administrar lo que existe cuando ganan las elecciones. 
Un caso complejo por su importancia es el de Perú, gobernado por el APRA, partido de larga tradición en la izquierda latinoamericana que ha realizado un gobierno sin muchas trazas de progresismo, capaz de continuar el impulso al crecimiento pero incapaz de mejorar significativamente las políticas de reducción de la pobreza, las diferencias territoriales y un acceso más igualitario a las oportunidades. Hoy con las crisis y el descenso del nivel de crecimiento los problemas de cohesión social se han agudizado.

Quien encabeza la oposición, Ollanta Humala, perdió las elecciones del 2006 apenas por 5\% de los votos en segunda vuelta. Es el fundador del Partido Nacionalista Peruano, que encarna la expresión más compleja de neojacobinismo militarista nacionalista y con escasas credenciales democráticas.

\section{Conclusiones}

Las distinciones que hemos realizado tienen, como es natural, sobreposiciones y puntos de intersección en la vida real. Estas sobreposiciones están presentes inevitablemente entre la segunda y la tercera distinción y entre la primera y la tercera; mucho más difícil es que se den entre la primera y la segunda. Mientras en la cuarta habría elementos de todos, compartiendo alegremente en la más estéril confusión. Pese a ello las distancias y diferencias son reales y en ocasiones excluyentes. Tal como no se puede ser de izquierda y de derecha al mismo tiempo, no se puede estar tampoco a favor y en contra de la democracia al mismo tiempo.

Es buena la diversidad y el debate, y es justo señalar que el progresismo no puede ni debe ser absolutamente homogéneo, aunque tampoco puede ser una suerte de salones del Far West donde algunos matones impongan la ley en base a la rapidez con sus armas, cualesquiera éstas sean.

Entre la homogeneidad y la ley de la selva hay un amplio espacio de ordenamiento político, con debate, reglas del juego democráticas, con espacios de crítica y de acción coordinada y proyecto colectivo.

Es legítimo apreciar la obra construida con ojos más o menos críticos; ello dependerá de las distintas sensibilidades, del lugar desde donde se protagonizan los cambios y hasta de rasgos de carácter. 
Nada de ello debería ser óbice para al final del debate actuar de manera concordada y leal.

Quisiera concluir señalando unos pocos elementos que me parecen indispensables para que el espacio progresista reformador se constituya en fuerza principal y perdurable.

1) La primera es la adhesión sin concesiones a la democracia en su dimensión procedimental. Aquella caracterizada por "la realización regular de elecciones libres, institucionalizadas y razonablemente competitivas, así como la vigencia de algunas libertades políticas tales como opinión, expresión, asociación, movimiento, acceso a medios periodísticos no monopolizados y similares" (O’Donnel 2008). Caracterizada en fin, porque las mayorías, cualquiera sea su dimensión, respeten a la minoría y donde éstas puedan, a su vez, transformarse en mayoría. Es éste y no las políticas económicas o sociales el punto decisivo de diferencia insalvable entre el progresismo reformador y un neo-jacobinismo que maltrate estos principios.

2) La segunda es la lejanía de las exclusiones: ni renunciar a la libertad en nombre de la igualdad ni a la igualdad en nombre de la libertad.

El convencimiento de que vivir en sociedad requiere sacrificar en algo la libertad individual, tener en cuenta la presencia del otro, desarrollar la solidaridad del género humano. La igualdad tampoco es absoluta, no es sinónimo de igualitarismo y menos de uniformidad, de ausencia de diversidad. Igualitarismo y libertad individual absoluta se excluyen, no así la libertad y la igualdad.

Se requiere, desde una perspectiva progresista, un compromiso persistente por lograr una sociedad más justa, para igualar las oportunidades, para asegurar a todos un mínimo civilizatorio. Ello requiere un ámbito público con capacidad y voluntad de acción, para hacer realidad las libertades positivas y el cumplimiento de los derechos económicos y sociales de manera progresiva. Como señala Vattimo: "la política de izquierda debe ser siempre una política activa de intervención" (Vattimo 2005), de no aceptación de la force des choses.

3) La tercera es la apertura y la curiosidad por lo nuevo, la disposición a revisar y corregir lo realizado. Ello no significa desvalorizar lo realizado, sino entenderlo como paso de un largo camino. 
Es la solidez de lo realizado lo que nos permite pensar con espíritu crítico cómo seguir adelante.

Es porque se construyó gradualmente una base sólida para un desarrollo equitativo que se puede pensar en hacer cosas distintas y nuevas para avanzar.

En el caso de la recién interrumpida experiencia chilena los ejemplos son muchos. Sin haber sacado contra viento y marea los enclaves más indignos de la dictadura en la Constitución actual, no se podría pensar hoy en una nueva Constitución. Sin salir del marasmo de la educación jibarizada que se encontró a fines de los ochenta, no se podría poner como eje del debate la calidad de la educación. Sin haber dado los pasos gigantescos en reducción de la pobreza, no podría hoy discutirse como un tema de sentido común una sociedad más igualitaria. Sin haber avanzado en un Chile macroeconómicamente sólido, contracíclico e integrado a la economía mundial, no se podría poner el tema ambiental y del cambio climático como agenda real.

4) La cuarta se refiere a la ética de la reforma. Ella es más difícil que la ética revolucionaria. Esta última tiene el vértigo de la refundación, las voces de la epopeya y la duración de un momento excitado y corto para transformarse después en opacidad, retórica alejada de la realidad, "parlamentarismo negro", en palabras de Gramsci. Corrupción, privilegios y abusos en nombre de una tierra prometida que jamás llegó y un hombre nuevo lleno de argucias para mal vivir en un mundo sin libertades ni abundancias. La ética de la reforma debe convivir con el mercado, con tiempos largos, sin mucha épica ni epopeya, sin religión política, y por ello puede ser gangrenada por la molicie, por la ventaja, primero pequeña y después más grande.

Como tiendo a ser más bien pesimista acerca de la naturaleza humana, creo que para evitar la decadencia y la corrupción se requiere el imperio objetivo de las normas que aminoren al máximo el arbitrio de los hombres. Más normas, entonces, para evitar los abusos en un proceso de cambios.

5) Una reflexión final, ser partidario de la gradualidad no significa desterrar el sueño. Pero sólo se sueña bien cuando los pies están en la tierra y se ha trabajado duro. No abandonar el largo camino de la reforma y empantanarse en atajos riesgosos no significa renunciar a los ideales. 
Digámoslo con Max Weber, quien no es sospechoso de irracionalismo alguno: "La política es un duro y lento trabajar de duras maderas, con una combinación de pasión y sensatez. Es, por supuesto, enteramente correcto y confirmado por toda la experiencia histórica, que lo que es posible nunca hubiera sido logrado si en este mundo los individuos no hubieran intentado repetidamente lo imposible" (Weber 1923).

\section{BIBLIOGRAFÍA}

Aricó, José: "El Difícil Camino de la Reforma Democrática”. En Alberto Adrianzén y Eduardo Ballón, Lo popular en América Latina ¿Una Visión de Crisis”. Lima: DESCO, 1992.

Bobbio, Norberto. Destra e Sinistra. Roma: Donzelli editori, 1994.

Castells, Manuel. Globalización, Desarrollo y Democracia: Chile en el Contexto Mundial. Santiago Chile: Fondo de Cultura Económica, 2005.

Giddens, Anthony. La Tercera Vía. Madrid: Taurus, 1999.

Julliard, Jacques. La Reine du Monde. Essai Sur la Democratie d'Opinion. París: Ed. Flammarion, 2009.

O’Donnel, Guillermo. "Los Desafíos Actuales de la Democracia y el Desarrollo". En O. Altimir, E. Iglesias y J. L. Machinea (eds.), Hacia la Revisión de los Paradigmas del Desarrollo en América Latina. Santiago: CEPAL/Segib, 2008.

Ottone, Ernesto y Sergio Muñoz. Después de la Quimera. Santiago: Random Mondadori, 2008.

Ottone, Ernesto y Crisóstomo Pizarro. La Osadía de la Prudencia. Santiago: Fondo de Cultura Económica, 2003.

Ottone, Ernesto y Ana Sojo. "La Racionalidad Política de la Cohesión Social". Pensamiento Iberoamericano $\mathrm{N}^{\circ} 1,2^{\mathrm{a}}$ Época, Madrid, 2007.

Ottone, E. y Carlos Vergara. Ampliando Horizontes: Las Siete Claves Estratégicas del Gobierno de Lagos. Santiago: Random Mondadori, 2007.

Rodotá, Stefano. Tecnopolítica, la Democracia y las Nuevas Tecnologías de la Comunicación. Buenos Aires: Losada, 1997.

Rouquié, Alain. "La Democracia en América Latina: Entre la Esperanza y la Sospecha". Cátedra Globalización y Democracia. Santiago: Universidad Diego Portales, 2009.

Sartori, Giovanni. La Democrazia in Trenta Lezioni. Milán: Mondadori, 2008.

Vattimo, Giovanni. "Conferencia en el Palacio de La Moneda". Santiago, Presidencia de la República, 2005.

Weber, Max. Political Writings. Cambridge: Cambridge University Press, 1994. 